\title{
Produção de Subjetividade e Militância Política dos Jovens do Movimento
}

\author{
Sem Terra no Semiárido Alagoano
}

\author{
Jadielma de Barros Alves* \\ Universidade Federal de Alagoas - UFAL, Maceió, AL, Brasil \\ ORCID: http://orcid.org/0000-0001-5636-9366 \\ Saulo Luders Fernandes** \\ Universidade Federal de Alagoas - UFAL, Palmeira dos Índios, AL, Brasil \\ ORCID: http://orcid.org/0000-0003-2335-0030 \\ Marcos Ribeiro Mesquita**** \\ Universidade Federal de Alagoas - UFAL, Maceió, AL, Brasil \\ ORCID: http://orcid.org/0000-0002-1642-0259
}

\section{RESUMO}

A pesquisa descritiva exploratória teve como objetivo analisar os efeitos psicossociais da subjetivação política dos/as jovens assentados/as do Movimento dos Trabalhadores Rurais Sem Terra. O estudo se amparou, como aporte teórico, em leituras da psicologia política, da psicologia social e da filosofia da diferença. O desenvolvimento metodológico se deu pela proposta cartográfica, referenciada em autores como Gilles Deleuze e Félix Guattari. Participaram dessa pesquisa dez jovens de um assentamento rural do semiárido alagoano, com idade entre 18 e 26 anos. Os instrumentos metodológicos utilizados foram grupos focais e diários de campo. Os dados analíticos produziram-se com base em três olhares analisadores: olhares para a militância política de uma juventude assentada, olhares para a violência simbólica vivida no seu cotidiano e olhares para os processos de (trans)formação política pelos quais passam, ao longo da trajetória de vida, nos contextos rurais e de militância de que fazem parte. Ao analisar os diferentes modos de vivenciar e significar a militância, considerase que é possível fortalecer o pertencimento dos sujeitos de um movimento social, a partir da junção das singularidades e valorização da heterogeneidade dos modos de ser e existir.

Palavras-chave: subjetividade, política, militância, juventude.

\section{Production of Subjectivity and Political Militancy of Young People from the}

\section{Landless Movement in the semiarid region of Alagoas}

\section{ABSTRACT}

The exploratory descriptive research aimed to analyze the psychosocial effects of the political subjectivity of the young settlers of the Movimento dos Trabalhadores Rurais Sem Terra. The study had as theoretical support readings of political psychology, social psychology and the

\begin{tabular}{|l|l|l|l|l|l}
\hline Estudos e Pesquisas em Psicologia & Rio de Janeiro & v. 21 & n. 1 & p. 10-29 & $\begin{array}{c}\text { Janeiro a Abril } \\
\text { de } 2021\end{array}$ \\
\hline
\end{tabular}


philosophy of difference. The methodological development took place through the cartographic proposal, referenced in authors such as Gilles Deleuze and Félix Guattari. Ten youngsters from a rural settlement in the semi-arid region of Alagoas, aged between 18 and 26 years, participated in this research. The methodological instruments used were: focus groups and field diaries. The analytical data were produced from three analytical perspectives: views of the political militancy of a settled youth, views of the symbolic violence experienced in their daily lives and views of the processes of political (trans)formation that they pass along the trajectory of life in rural and militant contexts which they are a part of. When analyzing the different ways of experiencing and signifying militancy, it is considered that it is possible to strengthen the belonging of the subjects of a social movement from the junction of singularities and valuing the heterogeneity of the ways of being and existing.

Keywords: subjectivity, politics, militancy, youth.

\title{
Producción de Subjetividad y Militancia Política de los Jóvenes del
}

\section{Movimiento Sin Tierra en la Región Semiárida de Alagoas}

\begin{abstract}
RESUMEN
La investigación descriptiva exploratoria tuvo como objetivo analizar los efectos psicosociales de la subjetividad política de los jóvenes colonos del Movimento dos Trabalhadores Rurais Sem Terra. El estudio tuvo como soporte teórico lecturas de psicología política, psicología social y filosofía de la diferencia. El desarrollo metodológico se llevó a cabo a través de la propuesta cartográfica, referenciada en autores como Gilles Deleuze y Félix Guattari. Diez jóvenes de un asentamiento rural en la región semiárida de Alagoas con edades comprendidas entre 18 y 26 años participaron en esta investigación. Los instrumentos metodológicos utilizados fueron: grupos focales y diarios de campo. Los datos analíticos se produjeron desde tres perspectivas analíticas: puntos de vista de la militancia política de un joven asentado, puntos de vista de la violencia simbólica experimentada en su vida cotidiana y puntos de vista de los procesos de formación política (trans) que transmiten a lo largo de la trayectoria. de la vida en contextos rurales y militantes de los que forman parte. Al analizar las diferentes formas de experimentar y significar militancia, se considera que es posible fortalecer la pertenencia de los sujetos de un movimiento social a partir de la unión de singularidades y valorando la heterogeneidad de las formas de ser y existir.
\end{abstract}

Palabras clave: subjetividad, la política, la militancia, la juventud.

Atualmente, o Movimento de Trabalhadores Rurais Sem Terra (MST) é considerado um dos mais destacados movimentos sociais da América Latina e reconhecido internacionalmente, principalmente por suas ações "[...] no campo da reforma agrária, da educação e da efetivação da democracia” (França, 2009, p. 134). É constituído como um movimento social que atua politicamente articulado a outros movimentos e instituições - 
como partidos políticos, igrejas, organizações não-governamentais e entidades nacionais e internacionais - e seus avanços em relação aos âmbitos de articulação são guiados pelas reivindicações e atuações sobre questões que vão além do interesse de lutas pela terra.

Isso se dá pelo fato de o MST compreender que a luta pela reforma agrária, no contexto brasileiro, passa também por uma luta contra o modelo econômico e político, tendo não apenas os/as latifundiários/as como inimigos/as, mas também e principalmente o modelo econômico neoliberal e imperialista (MST, 2007). Esse processo de ampliação de luta leva o MST a alinhar-se a outros/as atores/atrizes sociais, os quais também encaram esse modelo econômico como adversário (Leite \& Dimenstein, 2011).

Conforme o fortalecimento e a visibilidade das lutas pela terra, aspectos de ordem psicossocial pouco analisados passaram a ganhar destaque nos estudos realizados, tais como consciência política, identidade coletiva, relações de gênero dentro do contexto de militância, formação política e educação do campo.

A presente pesquisa vai ao encontro dessas investigações, ao se propor analisar aspectos relacionados à formação da militância política de jovens moradores/as de um assentamento rural do MST, almejando compreender os processos de subjetivação nela envolvidos e seus efeitos diários na vida dos/as jovens assentados/as. Como enfatizam Leite e Dimenstein (2011, p. 14), os aspectos de produção de subjetividade militante incidem sobre os/as participantes, com vistas a "[...] uma identificação destes com os propósitos políticos e princípios organizativos do movimento".

Para compreender os processos de subjetivação e seus contornos psicossociais, é necessário saber como o movimento se configura e quais as características que seus envolvidos lhe dão. Nas análises expostas por Leite e Dimenstein (2011), o MST é como um campo que atua em regimes - extensivo e intensivo. O primeiro assume caráter macropolítico e o segundo funciona como modo de singularização da militância e da heterogeneidade no cotidiano.

Segundo Guattari (1992), os processos de subjetivação afirmam a produção da diferença, as singularidades capilarizam os processos de formação subjetiva, na desconstrução de formações identitárias fixas e rígidas. O ritmo da construção da luta e da organização da vivência nos assentamentos rurais é marcado por “[...] rupturas, bifurcações, não-linearidade, continuidades/descontinuidades, construções/desconstruções, marcas/tempos internos diferenciados" (Gomes, 2001, p. 23) e, sobretudo, pela diferenciação. 
Guattari (1992), ao refletir sobre subjetividade no âmbito dos movimentos sociais, indica que é possível vê-los como construtores de subjetividades singulares que possibilitam forças criativas ao próprio movimento, consideradas uma resistência dentro da resistência.

\section{Juventude e Mundo do Campo: Lutas e Desafios}

A pesquisa foi trilhada no semiárido nordestino, em uma comunidade campesina do agreste de Alagoas, localizada no assentamento rural do Movimento Sem Terra Dom Hélder Câmara, mais conhecido como Assentamento Rendeira, situado no município de Girau do Ponciano. É o maior assentamento em extensão territorial e em capacidade de famílias e por característica também de extensão territorial. O assentamento é formado por uma microdivisão interna, composto pela junção de seis agrovilas, as quais agregam aproximadamente 300 famílias e contêm expressiva presença de jovens, entre 12 e 35 anos de idade (Santos, 2009).

Localizar geopoliticamente a construção do conhecimento é fazer emergir um olhar crítico que questiona a construção dos saberes em pressuposições hegemônicas, abstratas e pretensiosamente universais. De acordo com Ximenes e Camurça (2016), o semiárido brasileiro equivale a $18,2 \%$ do território nacional, abrange os estados do Nordeste e parte de Minas Gerais: "No semiárido nordestino vivem cerca de 22 milhões de pessoas (13\% da população brasileira), o que representa $46 \%$ da população nordestina cuja concentração maior encontrada é nas áreas rurais" (Ximenes \& Camurça, 2016, p. 177).

O semiárido de Alagoas é definido em três sub-regiões: o agreste, o médio sertão e o sertão. O agreste apresenta-se como um território de transição entre a zona da mata, o litoral e o sertão. Esse meio caminho possibilitou à sua formação o encontro de elementos de duas formas de organização social presentes na vida colonial alagoana: indígenas que fugiam do massacre do sertão e buscavam, em novos territórios, construir os aldeamentos; e comunidades negras, as quais, em um processo de migração forçado às empreitadas da guerra travada no Quilombo dos Palmares, procuravam nas terras do interior a liberdade almejada (Lusa, 2013).

O território agrestino forma-se na resistência a esses dois massacres, que trazem consigo um projeto de sociedade carregado de mandonismos políticos, coronelismos e violências. As resistências produzem táticas de organização coletivas que enriquecem a capacidade de ação política e o fortalecimento de vínculos comunitários entre seus pares. 
Nas regiões do Nordeste, o semiárido alagoano ocupa a menor extensão do chamado Polígono das Secas. O semiárido de Alagoas apresenta uma diversidade de produções agrícolas dispostas em pequenos minifúndios, que colaboram para a existência e a perpetuação da unidade camponesa, indígena e quilombola. A presença de minifúndios no agreste e no sertão não descarta a concentração de renda, de poder e também de terras nas mãos de poucos proprietários. Estes, por meio de seu poder econômico, exercem sua força política de forma paternalista e coronelista (Lusa, 2013).

Mesmo com todas as dificuldades políticas e escassez de recursos no cotidiano das mulheres e homens do semiárido, de acordo com Lusa (2013), a capacidade de resistir e produzir uma autonomia de organização coletiva faz parte do dia a dia dos agrestinos e sertanejos.

A partir de uma perspectiva sociológica, os locais são construídos por aspectos históricos, econômicos, sociais, culturais, entre outros, os quais influenciam no significado que o espaço passará a ter para os sujeitos que neles convivem (Paulo, 2013). No caso do espaço rural, o modo de vida gerado não depende apenas do espaço físico com o campo e trabalho na terra, mas com a ligação subjetiva instaurada através da relação de convivência e trocas com o local, na formação de um território de relações, de vida, de experiência e de coletividades (Oliveira \& Prado, 2013). A possibilidade de produção de laços comunitários de solidariedade e apoio configura exemplos de alguns dos aspectos que refletem decisivamente na construção subjetiva dos sujeitos que vivem nesses locais (Lopes \& Carvalho, 2017).

Apesar dos pontos positivos, o meio rural apresenta algumas dificuldades que se destacam por impactar mais diretamente a vida diária dos/as jovens no que diz respeito ao acesso a alguns direitos básicos, como a escola, o lazer e o trabalho. Estes são fatores que impedem a permanência dos/as jovens em suas comunidades (Castro, Martins, Almeida, Rodrigues, \& Carvalho, 2009). Junto a essas dificuldades, os/as jovens rurais também são vítimas de violência simbólica que, diante dos processos de industrialização e urbanização, afirma o território rural como inferior e subalterno - violência esta geralmente ligada às práticas culturais que envolvem relações de gênero, classe ou grupo social, tidas como naturais (Fernandes, Ribeiro, \& Oliveira, 2018).

Além de serem estigmatizados nos espaços urbanos como roceiros/as, matutos/as e caipiras, às vezes, são tratados/as em casa como urbanos/as demais para se manterem interessados/as em continuar o trabalho dos pais/mães na terra. Quando se observa o funcionamento dessas relações cotidianas do/a jovem em contexto rural, percebe-se que frequentemente os/as jovens carregam limitações quanto ao espaço de participação, 
capacidade de serem ouvidos/as ou dificuldade para conseguir se colocar em espaço de decisão, por considerarem possuir pouca seriedade, experiência ou mesmo por “deslegitimação dos/das filhos/as por serem jovens” (Castro, 2009, p. 194).

Castro et al. (2009) fizeram um levantamento bibliográfico relacionado à juventude rural brasileira e a associaram a elementos como migração e invisibilidade. Na maioria dos estudos, verificou-se uma visão reduzida sobre a juventude, ignorando-se os espaços sociais e lugares que ocupa, sem se aprofundar no modo em que ela está situada na família e na sociedade.

Os movimentos sociais geralmente se constroem e se fortalecem por meio dos momentos de encontros e discussões, gerando espaços para aproximação dos/as interessados/as e envolvidos/as em determinados assuntos, assim como cooperando para consolidar vivências relacionadas à militância e às experiências como atores/atrizes políticos/as (Castro, 2009).

A militância na luta por políticas públicas que contemplem as necessidades da juventude e melhorem os contextos em que vivem pode representar mais do que a procura de autonomia política, econômica e visibilidade (no caso dos jovens rurais), reverberando aspectos subjetivos de pertencimento e enraizamento com o modo de vida. De acordo com Falkembach (2006), a luta pela terra vai além da conquista por um lugar social de referências simbólicas resgatadas: ela possibilita o pertencimento a ela, o que faz com que adquira muito mais que valor econômico, ao gerar também significado existencial e atuar na produção de um modo de viver.

Assim, diante dos contextos vividos por jovens rurais, é importante destacar o cuidado que a ciência deve ter, ao entrar em contato para pesquisar os espaços e modos de vida rurais, de forma a atentar para não reproduzir discursos que reduzam, criminalizem e marginalizem os modos de vida dos homens e mulheres do campo, mas que busquem formas metodológicas e relacionais de produzir, com estas pessoas, narrativas capazes de afirmar seus modos de viver e seus encontros com a vida política (Fernandes, 2014).

\section{Caminhos da Pesquisa}

A experiência de pesquisar é semelhante ao início de uma viagem a uma cidade desconhecida, permeada por ideias pressupostas que direcionaram a escolha do lugar de embarque, as expectativas sobre o que se encontrará e os afetos que se podem despertar por lá. Ao longo da viagem, depois de algum tempo de imersão no local de visita, as ideias 
pressupostas cedem lugar às experiências concretas, as quais fazem com que a dita cidade, muitas vezes, seja referenciada por novas cartografias, significados e afetos (Varela, Thompson, \& Rosch, 1993).

Atualmente, tanto a psicologia como outras áreas das ciências humanas e sociais tendem a provocar seus/suas pesquisadores/as a buscarem métodos de fazer pesquisa (Romagnoli, 2009) que não predeterminem o que procuram encontrar, ou mesmo representar, de forma objetiva e neutra, na realidade estudada, convertendo a mesma em dados coletados.

Na busca por uma relação com o conhecimento que se pautasse em um compromisso científico, ético e político com os/as participantes do estudo, a presente pesquisa foi direcionada pelo método cartográfico, baseado nas ideias de Gilles Deleuze e Félix Guattari, pela proposta de realização de um trabalho de análise que não desconsidere o protagonismo da pessoa pesquisada, ou pratique uma coleta "extrativista", mas, ao contrário, que consiga ser ao mesmo tempo descritiva, interventiva e produtora de emergências subjetivas à transformação do viver (Romagnoli, 2009).

A prática da pesquisa cartográfica produziu, no desenvolvimento desta investigação, implicações para o campo no contato com o território e os/as participantes. Os movimentos aconteceram conforme a demanda e concordância das pessoas, do cotidiano e das relações ali estabelecidas. Isso revelou a impossibilidade de o processo ser vivido somente pelo/a pesquisador/a e evidenciou a necessidade de considerar todos os envolvidos - sujeitos e territórios - enquanto protagonistas da produção de conhecimento.

A investigação foi desenvolvida por meio da técnica de grupo focal, realizada em quatro encontros de um grupo composto por dez jovens: sete do sexo feminino e três do sexo masculino, entre 18 e 26 anos de idade, moradores de um assentamento do MST no agreste alagoano. Além do grupo focal, foi utilizado também o diário de campo, para registros cartográficos dos acontecimentos e das cenas experienciadas na pesquisa.

A pesquisa iniciou com a preocupação de conhecer as demandas dos/as jovens assentados/as. Uma das questões problematizadas foi a necessidade de discutir a vivência militante da juventude. Frente a essa demanda, foram propostos os grupos focais, para se buscar debater como se compõem os processos de subjetivação da juventude assentada e quais os seus efeitos cotidianos na produção da vida diária dos/as jovens.

O trabalho foi desenvolvido em cinco etapas: 1) levantamento bibliográfico e revisão sistemática sobre a temática militância política e subjetividade; 2) conversa inicial com a liderança comunitária da juventude do MST, para o aceite, viabilidade e negociações para efetivação da pesquisa, na comunidade; 3) realização de quatro grupos focais, com o objetivo 
de promover um espaço de escuta e compreender os efeitos cotidianos da militância, na vida dos/as jovens. Os temas disparadores para as discussões dos grupos focais apresentados e construídos com os/as jovens foram associados à história do MST, fazendo relação entre subjetividade e política, participação política de jovens na atualidade, e exercício da participação política no movimento; 4) análise dos processos disparados na pesquisa; 5) retorno à comunidade investigada, para devolutiva e debate dos conhecimentos produzidos.

Neste trabalho cartográfico, tendo o diário de campo como guia narrativo da pesquisa e com os encontros com os/as jovens nos grupos focais, emergiram analisadores que geraram afetações e produziram rupturas analíticas em relação à realidade estudada. Tais rupturas e acontecimentos foram definidos como olhares, ou entradas para análise das experiências produzidas no decorrer do estudo. Dentre variados acontecimentos, serão compartilhados três olhares que marcaram as experiências dos grupos focais. São eles: 1) olhares para a militância política de uma juventude assentada; 2) olhares para a violência simbólica vivida no cotidiano da juventude assentada; 3 ) olhares para os processos de (trans)formação política.

\section{Olhares para a Militância Política de uma Juventude Assentada}

Os espaços institucionais do assentamento são, em sua maioria, mediados pelos adultos, o que transforma esses espaços em lugares de invisibilidade para os/as jovens. Os modos de atuação política institucionalizados são produzidos por uma visão adultocêntrica, a qual concebe os modos políticos de ação dos jovens como inadequados ou imaturos, em face dos moldes clássicos de militância. Essa invisibilidade vivida pela juventude é relatada nos estudos de Castro et al. (2009), para quem os/as jovens estudados/as descrevem vivências de subordinação devido à sua idade, entendida como falta de experiência, frente a militantes de mais idade.

Apesar de o protagonismo político ser relatado pelos/as jovens assentados/as, em suas ações e desejos - nas reuniões realizadas entre a juventude do assentamento, para compartilhar experiências, nos luais e práticas de cultura organizadas por eles, na participação dos encontros regionais, estaduais e nacionais e em pautas do movimento que necessitam de suas mobilizações - eles/as afirmam que o seu modo de atuação nem sempre é visibilizado, principalmente em momentos de decisão. A visibilidade aparece nos relatos e debates suscitados entre eles/as e no compartilhar de suas experiências com outros/as jovens.

A sutil reprodução de um protagonismo político baseada em uma lógica adultocêntrica produz o enquadramento dos/as jovens em espaços normatizadores e subalternizantes, o que 
lhes retira a capacidade de identificação e reconhecimento da atuação, de maneira autônoma e legítima, nos espaços institucionais, de sorte que sua ação política é construída de forma autônoma, em espaços marginais do movimento. A despeito de essa marginalidade precarizar seu protagonismo político institucionalizado, ela possibilita um lugar de autogestão e ação política autônoma que enseja a organização e a afirmação dos/as jovens militantes.

Esse olhar entre invisibilidade e visibilidade política dos/as jovens no contexto rural foi suscitado durante o segundo grupo focal, quando foi realizada uma atividade que funcionava com base na escolha de um objeto - tanto levado pelas/os próprias/os participantes quanto pela pesquisadora, tais como livro, enxada, bandeira, boné, camisa - que destacasse a ligação deles/as com o movimento e provocasse comentários sobre a representação daquele símbolo. Uma jovem de 18 anos escolheu o boné do MST para fazer alusão ao orgulho que sentia em usar os acessórios que a identificam como parte do movimento. No entanto, quando a mesma contextualizou sua fala, dizendo "Eu sou filha de assentado e tenho muito orgulho do movimento, não me envergonho de usar [...], as outras meninas que também são filhas de assentado devia fazer o mesmo [...]” (J1, uma jovem de 18 anos, diário de campo do segundo encontro), houve algumas tensões no grupo devido à centralidade dada aos parentes como “os/as assentados/as", e a vinculação dos/as jovens ao movimento a partir dos pais e mães. Cabe frisar que a maioria dos/as jovens participantes já nasceu no assentamento e, apesar de terem participado de movimentos de rua, mobilizações para melhoria das condições de vida e garantia de direitos no assentamento, não vivenciaram o processo de ocupação de terras do movimento. O vínculo com o assentamento se dá através de pais, mães ou parentes.

Ao longo da atividade e da exposição dos objetos e significados, ao mesmo tempo em que alguns/mas jovens faziam referência à militância, centralizando-a nos/as pais/mães, levantaram discussões e relataram momentos que vivenciavam enquanto sujeitos protagonistas. Um dos objetos evidenciados por uma jovem foi a camisa, ao contextualizar o orgulho de fazer parte do movimento, mesmo quando não são reconhecidos/as como trabalhadores/as em busca de melhoria para a sociedade no geral, reafirmando, em sua fala, que "[...] a crítica vem muito por falta de conhecimento sobre o que nós somos" (J2, uma jovem de 19 anos, diário de campo do segundo encontro).

Continuou a comentar também que há casos de pessoas no próprio assentamento que não se orgulham de seu pertencimento e, por isso, evitam qualquer exposição que tenha relação com o movimento. Contudo, acreditam que estes casos também são por falta de conhecimento da causa e por se deixarem persuadir pela forma pejorativa com que a mídia classifica o MST. J4 reforça essa ideia ao afirmar que "[...] ser assentada não quer dizer que 
a pessoa faça parte da luta. Muitos até criticam o movimento que eles mesmos fazem parte" (J4, uma jovem de 21 anos, diário de campo do segundo encontro).

Nesse mesmo encontro, já próximo ao encerramento do grupo focal, a pesquisadora fez uma provocação ao grupo, indagando se eles/as consideravam que existiria um "perfil de militante". Uma das jovens respondeu que sim, e descreveu como seria: "[...] ter coragem de estar em enfrentamentos com policiais, por exemplo. Muitas coisas que a gente tem medo, mas militante tem coragem de fazer" (J1 uma jovem de 18 anos, diário de campo do segundo encontro). Afirmou ainda não estar preparada para ser uma militante, por seu medo de se posicionar, já que, para ela, militante precisa "falar sem medo".

As cenas realçadas expressaram momentos que revelam a sutil reprodução de um perfil militante, o qual não permite a visibilidade de outras formas de protagonismo político que não sejam aquelas já internalizadas como padrão, mas também o reconhecimento e orgulho de fazer parte do movimento.

Conforme discutido, o MST atua em modo de regimes extensivo e intensivo, com tendência mais ligada ao extensivo, efetivando discursos que orientam os modos de ser sujeito militante do movimento, “[...] designando lugares, dizeres e fazeres para cada identidade forjada" (Leite \& Dimenstein, 2011, p. 57). Tal situação direciona-se à homogeneização e generalização nas formas de pensar e agir, as quais determinam o nível de atuação e protagonismo apenas em função da existência de certas características.

Vinadé e Guareschi (2007) assinalam que aspectos como esses, de homogeneização e generalização, são alvos de crítica, já que certos critérios colaboram tanto para a rigidez e o enraizamento das identidades, ao desconsiderar os modos subjetivos de vivenciar a militância, quanto para comprometer uma marca histórica da construção do movimento, que é valorização da heterogeneidade, seja de pautas de reivindicações, seja de figuras capazes de compor as frentes de lutas.

O fenômeno da homogeneização não acontece em forma de imposição ou orientação para determinado fim. Dá-se de maneira sutil, quer por meio de processos subjetivos construídos ao longo da militância - com a ideia de que existiria um modelo ideal a ser seguido -, quer pela consequência que esse ideal gera, como a falta de espaços e dispositivos que contemplam os/as jovens também como protagonistas, ao alimentarem um imaginário centralizado no adulto.

Os estereótipos homogeneizadores, embora remodelados, são sutilmente propagados e evidenciados a partir da relação que pode ser feita entre o "homem/mulher sisudo/a", como aquele/a que precisa "ter coragem de estar em enfrentamentos com policiais" ou, ainda, 
aquele/a "que só fala em política", o que gera a compreensão de poder se considerar militante somente se tiver a "coragem para falar" (J1, uma jovem de 18 anos, diário de campo do segundo encontro) e expor sua opinião, em qualquer situação. Esses fatores reforçam a existência da reprodução da imagem estereotipada do/a militante.

Os/as demais jovens, assim como $\mathrm{J} 1$, ao se apropriarem desses discursos que alimentam um modelo ideal de militante, acabaram por não se considerar um/a deles/as. Embora se envolvam de forma prática, afetiva e subjetiva, com vivências diárias de militância - seja em encontros formativos, seja em protestos ou compromissos voltados para as demandas do movimento, do assentamento e de melhorias sociais - que se caracterizariam como atuação política ativa, ainda não as enxergam como suficientes.

O não-lugar imposto aos/às jovens que não contemplam determinadas características semelhantes ao estereótipo de "[...] homem barbudo, jovem, sisudo, que só fala em política em todos os momentos da vida, que não relaxa, que não tem vida social e familiar [...]" (Vinadé \& Guareschi, 2007, p. 69) é, muitas vezes, absorvido e refletido por eles/as mesmos/as. Isso reforça o fato de que, frequentemente, o reconhecimento da experiência juvenil se dá por uma mediação, adulta ou institucional, o que revela a permanência do lugar de tutela reservado ao jovem (Souza, Marçal, Lino, Mayorga, \& Prado, 2012). Nesse sentido, menos emancipa do que os/as torna atores/atrizes políticos/as.

\section{Olhares para a Violência Simbólica Vivida no Cotidiano da Juventude Assentada}

Diante dos estigmas sociais repercutidos na sociedade sobre os/as sem-terra, não é difícil imaginar o quanto seus/suas membros/as são marginalizados/as e referenciados/as negativamente por serem do movimento. Esses fenômenos de violência evidenciam-se no cotidiano dos/as jovens, não somente em forma de ataques pessoais, como também de exclusão vivida em contextos diversos.

No primeiro grupo focal, quando perguntados/as como eram reconhecidos/as socialmente, enquanto militantes do movimento, J3 (uma jovem de 18 anos, diário de campo do primeiro encontro) relatou ter precisado pegar o transporte coletivo para ter acesso a um povoado próximo, em um dia em que estava ocorrendo uma manifestação para sensibilizar a Prefeitura a dar atenção a algumas questões negligenciadas no assentamento. Nesse dia, a mesma ouviu, durante o percurso, comentários pejorativos sobre os/as militantes: "Vagabundos/as! Ladrões/as de terras, que não trabalham e querem tomar a terra dos/as outros/as!" (diário de campo, primeiro encontro). 
Diante desse relato, outros/as jovens confirmaram o quanto é comum ouvirem esses tipos de falas equivocadas, por quem não conhece a realidade do movimento. Esse tipo de situação, por mais indesejado e humilhante que seja, segundo as expressões dos/as jovens, não os/as imobiliza ou desanima para a continuidade de suas lutas. O modo comum de revidar os ataques é expor que trata-se de uma luta por direitos que são legítimos, além de sublinharem os benefícios da reforma agrária para o desenvolvimento do campo e da minimização das desigualdades.

No segundo grupo focal, outras discussões levaram ao compartilhamento das experiências de preconceito que sofrem. Em destaque, chamou a atenção o relato de uma jovem de 21 anos, J4, estudante de uma faculdade na cidade vizinha ao seu município, a qual, ao se locomover do assentamento à cidade, sofre cotidianamente violências e discriminações. Referiu-se à situação de precisar tomar uma van na rodovia relativamente próxima ao assentamento. No horário de retorno, às 23 horas, o local já se encontra isolado e vazio, e ela pergunta ao motorista se ele poderia deixá-la na casa de sua tia, um lugar mais seguro. $\mathrm{O}$ motorista diz que não, pois as pessoas que usavam a van já reclamavam só pelo fato de ele parar naquele ponto. Quando ela indagou o porquê, ele respondeu que era pela situação de os/as moradores/as da região serem do Movimento Sem Terra. Ela contou que, depois de ele dizer isso, ficou calada, pois, se fosse discutir com o motorista e demais pessoas, poderia perder a chance de ir à faculdade. Apesar do constrangimento e da não aceitação por todos/as que precisam partilhar daquele espaço com ela, não deixou de ir de van, pois, do contrário, comprometeria o sonho de formar-se como professora e poder contribuir com a educação do campo e do seu próprio assentamento.

Episódios de discriminação e humilhação foram descritos como comuns por outras pessoas do grupo, embora tenham afirmado também que, depois de algumas experiências, já não se afetam tanto como quando se iniciaram na militância. Um dos relatos feitos por uma jovem (J7) foi de que quando as pessoas da comunidade chegam nos espaços e se apresentam como pessoas do movimento, geralmente passam por constrangimentos. Ela enfatizou: "Se você não tiver noção do que você é, você se sente diminuída" (J7, uma jovem de 22 anos, diário de campo do segundo encontro). Prosseguiu, dizendo que é comum chegar a espaços e, ao se apresentarem como do movimento, as pessoas os/as olharem da cabeça aos pés, em busca de características que os/as humilhem. Concluiu a fala, ressaltando que "[...] as pessoas têm a ideia de que, porque somos sem-terras, precisamos andar todo 'esmalambado', mas não é. A gente luta por uma transformação social. A gente luta por uma melhoria de vida" (J7, uma jovem de 22 anos, diário de campo do segundo encontro). 
Ao longo desse mesmo encontro, um jovem de 23 anos afirmou que "[...] pessoas no geral, do interior, sofre preconceito por ser do interior, mas no caso da gente, por ser de assentamento, sofremos mais preconceito ainda" (J5, um jovem de 23 anos, diário de campo do segundo encontro).

Essas situações vividas pela juventude assentada caracterizam-se como violência simbólica, que gera sofrimento e desgastes psicossociais nas relações cotidianas. Para Caume (1994), a violência física é mais fácil de ser identificada. No entanto, a violência simbólica, apesar de mais sutil, é tão ou mais perversa e de impacto na vida do sujeito, ao servir como artifício de afirmação ou intensificação da dominação social de uns/umas em contraposição à subalternidade e opressão de outros/as. O cerne desse tipo de violência está na privação do poder que afeta a liberdade e o direito de autonomia do/a outro/a. Segundo Caume (1994), até a modernização tecnológica pode ser pensada como processo de violência igualmente simbólica, quando visualizada a partir da negação da identidade social e cultural do campesinato, no caso dos/as jovens campesinos/as.

É possível perceber que, apesar da negação das diferenças, atribuídas tanto ao movimento social quanto às categorias juventude e rural, a juventude rural assentada do MST tem conhecimento da legitimidade da causa pela qual lutam e a que pertencem. Esse fenômeno de compreensão e entendimento da causa de que fazem parte potencializa a capacidade de não se abaterem ou desistirem de suas convicções.

Esses/as jovens assentados/as implicados/as no estudo consideram que as críticas vindas de pessoas sem conhecimento da realidade que vivenciam não podem ser razão de estagnação dos modos de vida que levam. O pertencimento enquanto jovem rural e a identificação junto aos seus iguais, nos encontros, nas práticas diárias, nas místicas, os/as fazem resistir e produzir narrativas e afetos resilientes e resistentes.

\section{Olhares sobre os Processos de (Trans)formação Política}

As modificações construídas através das formações políticas e do engajamento no movimento geram ações que refletem (trans)formações quer em âmbito social, quer na forma de ser e lidar com o mundo, com o movimento, com a militância e consigo mesmo. Os impactos causados pelas experiências e trocas nos espaços formativos reforçam sentimentos de pertencimento ao movimento, bem como as próprias convicções da luta política da juventude para transformação da realidade que a circunda. 
No quarto encontro, enquanto se discutiam assuntos relacionados à temática “juventude, participação política e contemporaneidade”, um jovem de 24 anos (J6), graduando em Educação Física, contou um pouco do trajeto político que o levou a atualmente estar no movimento de forma efetiva. J6 destacou que cresceu no movimento mas que não se reconhecia como militante, pois, durante sua infância, no período de Educação Básica, as professoras contratadas para lecionar nas escolas do assentamento, onde ele e demais crianças assentadas estudavam, transmitiam histórias levianas, interpretadas por ele como "outra visão do que é o movimento" (J6, um jovem de 24 anos, diário de campo do quarto encontro).

Ele relatou ser frequente o não reconhecimento do movimento por parte de suas professoras da Educação Básica, o que as fazia transmitir conteúdos que reforçam as imagens marginalizadas dos/as militantes. J6, narra que as professoras “[...] passava como a que era vista através da mídia, e não da realidade vivenciada por eles [trabalhadores rurais sem terra], por isso muita das vezes a criança já crescia pensando em não ser do movimento, em não fazer parte da luta” (J6, um jovem de 24 anos, diário de campo do quarto encontro). Ele se incluiu entre essas crianças que não se identificavam com o movimento e atribuiu essa negação de pertencimento e militância ao modo pejorativo como os/as educadores/as interpretavam a história do MST, os/as quais, em vez de procurar se apropriarem da realidade dos assentamentos e acampamentos, se baseavam no que a mídia transmitia e reproduzia, em forma de ataque contra os/as moradores/as assentados/as. Ele declarou que "[...] quem era do assentamento se sentia inútil" (J6, um jovem de 24 anos, diário de campo do quarto encontro) durante os discursos das professoras.

Os afetos descritos por J6 podem ser definidos como experiências de subalternidade e desigualdade que reificam a vida de grupos sociais em relação a formas hegemônicas de ser e existir. Gonçalves Filho (2007) conceitua esse tipo de experiência como humilhação social, ou seja, experiências de subalternidade que objetificam a vida de sujeitos e grupos pela referência a modos hegemônicos de existência. Apesar de tais experiências de humilhação atingirem as pessoas individualmente, elas são dirigidas em função dos grupos a que pertencem - nesse caso, o MST. A humilhação social requer um sujeito e seu grupo, que se torna objeto de desumanização de um outro que se impõe como norma e enquadre do viver. Não há experiência de humilhação social sem o antagonista que impõe, de forma violenta, enquadres normativos de viver, na tentativa de subjugação do outro.

Experiências análogas de humilhação social vividas em contextos rurais foram relatadas nos estudos de Fernandes, Zakabi e Calegare (2016), que refletem sobre a experiência de humilhação social em três contextos diversos de comunidades rurais 
(ribeirinhos, quilombolas e assentados). De acordo com o autor, as experiências comuns de humilhação sofridas pelas comunidades pesquisadas passam pela negligência de direitos e a violência vivida no mundo rural brasileiro. Além disso, diante de tais relações de subalternidade, as comunidades mobilizam forças de afirmação de suas lutas, por meio dos debates e espaços de grupo, a fim de compartilharem suas vivências e apresentarem alternativas coletivas de fortalecimento para a luta social.

O relato de J6 converge para as formas de afirmação da luta política, como citado por Fernandes, Zakabi e Calegare (2016), no momento em que entra em contato com outras narrativas e espaços grupais de compartilhamento de suas experiências, começando a se identificar com o movimento e conceber o mesmo de outra forma (quando se tornou jovem, começou a ter acesso a outras fontes de informação e dispositivos - como participação em grupos de formação, encontros com a juventude, espaços de trocas de experiências entre jovens também assentados/as -, de sorte a adquirir discernimento sobre o que de fato era o movimento), assim, fazendo parte e estando até hoje ciente da legitimidade da causa da militância e da necessidade dos enfrentamentos equivocadamente vandalizados, que servem para garantia da conquista de direitos individuais e coletivos. Concluiu por expressar que não sente arrependimento nem tem pretensão de sair. Pelo contrário, planeja terminar a graduação e dedicar-se ao ensino de uma educação contextualizada do campo.

Essa experiência descrita pelo jovem aponta para o fato de os espaços de formação política não se restringirem aos cursos de formação de base, feitos em momentos específicos ou para pessoas específicas. De fato, devem estar sintonizados com a necessidade da existência contínua de grupos que potencializem e motivem os membros de qualquer faixa etária ou tempo de envolvimento no movimento, para efetiva atuação.

A consolidação de espaços de fortalecimento e troca possibilita o compartilhamento de “[...] valores de ordem mais subjetiva como amizade e o prazer, por exemplo, que podem se firmar como dispositivos importantes para a organização dos/as jovens e para o processo de subjetivação política" (Mesquita, Bonfim, Padilha, \& Silva, 2016, p. 295). O estudo de Leite e Dimenstein (2011) também demonstra como a amizade atua enquanto dispositivo político de fortalecimento e ação militante para os/as integrantes do MST. São esses afetos que circulam em outras instâncias de formação, atuando como elementos na transformação e organização da luta social.

Poder construir espaços de partilha e acolhimento entre os/as jovens permite trocas de vivências comuns, como as angústias, os enfrentamentos, as superações e as conquistas alcançadas por meio da militância, o que torna as experiências vividas por eles/as mais 
legítimas e reforça a importância e a potência dos espaços de socialização entre os pares, na formação e transformação subjetiva e política. Dessa forma, os espaços de trocas de experiências e vivências entre os/as jovens fortalecem os vínculos, o sentimento de coragem e a identificação com a luta, além de proporcionarem a criação de uma rede afetiva com impactos positivos para a estrutura psicológica, auto estima, segurança e satisfação das necessidades dos/as militantes. Dispositivos metodológicos como os grupos focais desenvolvidos para a construção da pesquisa têm, inclusive, capacidade de criar esses espaços que propiciam o compartilhamento de vivências, construção de formação política e transformação social e pessoal.

Os espaços de trocas possibilitam "a formação de sentimento de pertencimento e enraizamento no espaço, ressaltando a necessidade de um lugar para expressão de sua subjetividade" (Lopes \& Carvalho, 2017, p. 5), ao mesmo tempo em que evidenciam o quanto é prejudicial para os/as jovens estarem em espaços que não dialogam com suas experiências e serem alvos de preconceitos e discriminação, baseados em estereótipos e falsas conclusões, que os/as fragilizam e colocam em risco a identificação com o movimento.

\section{Considerações Finais}

O desejo de investigar as produções subjetivas envolvidas nos processos de formação política da juventude rural militante foi causado por uma demanda do próprio assentamento, e desenvolveu-se pelo entendimento da posição que estes/as jovens ocupam, enquanto protagonistas. A partir do diálogo travado nos grupos focais, conhecemos jovens que desenvolvem diversas ações comunitárias e políticas no assentamento, que vão da realização de reuniões e atividades culturais à participação em processos e mobilizações em pautas nas quais acreditam. No entanto, essas ações nem sempre são reconhecidas. Os espaços institucionais do assentamento são, em sua maioria, mediados pelos adultos que, muitas vezes, concebem os modos de atuação política dos/as jovens como inadequados ou imaturos frente aos moldes clássicos de militância.

Também encontramos jovens que, em função dos marcadores sociais, políticos e territoriais que os/as atravessam, se deparam frequentemente com situações de discriminação e humilhação, concretizadas no cotidiano e que se manifestam em forma de ataques pessoais e dirigidos ao coletivo.

Apesar das dificuldades surgidas em função da invisibilidade, do não-lugar e da violência e preconceito que vivenciam, os/as jovens pesquisados/as seguem construindo 
narrativas, ações e desejos que realçam a dimensão do seu protagonismo, junto às lutas empreendidas pelo movimento. A participação na pesquisa, tendo os grupos focais construídos com a própria juventude, permitiu que os/as jovens reafirmassem a possibilidade deles/as mesmos/as produzirem seus espaços e modos de atuação, criando estratégias mais efetivas para o compartilhamento de experiências e o fortalecimento de vínculos. Essas estratégias se desdobram na construção de espaços políticos de caráter formativo, alternativo, lúdico e artístico, em âmbito local e regional. A pesquisa ainda avançou no aprofundamento da relação entre a academia e o movimento, dando sequência a outros diálogos horizontalizados e trocas de experiências com os/as jovens.

\section{Referências}

Castro, E. G. (2009). Juventude rural no Brasil: processos de exclusão e a construção de um ator político. Revista Latinoamericana de Ciências Sociais, Niñez y Juventud, 7(1), 179-208.

Recuperado

de

http://www.scielo.org.co/scielo.php?script=sci_arttext\&pid=S1692-

$715 X 2009000100008 \& \operatorname{lng}=$ en\&tlng=pt

Castro, E. G., Martins, M., Almeida, S. L. F., Rodrigues, M. E. B., \& Carvalho, J. G. (2009). Os jovens estão indo embora? A juventude rural e a construção de um ator político. Rio de Janeiro: Mauad X, Seropédica, EDUR.

Caume, D. J. (1994, Julho). Tecnologia, Violência e Perspectiva de Desenvolvimento Agrícola do Movimento dos Trabalhadores Rurais Sem Terra. In Anais do XXXII Congresso Brasileiro de Economia e Sociologia Rural (SOBER). Brasília, DF, Brasil.

Deleuze, G. (1992). Conversações. Rio de Janeiro: Editora 34.

Falkembach, E. M. F. (2006). Socialização e individuação: MST, uma estilística da resistência. Rio Grande do Sul: Unijuí.

Fernandes, S. L. (2014). Revisitando os saberes psicológicos: Reflexões por uma psicologia do campo. Cadernos de Subjetividade, (16), 85-103. doi: 10.2354/cs.v0i16.38537

Fernandes, S. L., Zakabi, D., \& Calegare, M. G. A. (2016). Humilhação social e contextos rurais: Discussões a partir de pesquisas em três comunidades rurais. Revista Psicologia Política, 16(37), 287-303. Recuperado de http://pepsic.bvsalud.org/pdf/rpp/v16n37/v16n37a04.pdf

Fernandes, S. L., Ribeiro, J. M., \& Oliveira, E. C. S. (2018). Violência vivida por jovens rurais: Enfrentamentos e suas táticas de resiliência. Revista Amazônica (online), 22(2), 
98-120.

Recuperado

de

https://periodicos.ufam.edu.br/index.php/amazonica/article/view/5123/4092

França, J. N. (2009). Projeto democrático socialista do MST: Alguns elementos linguísticoideológicos. Maceió: EDUFAL.

Gomes, I. Z. (2001). Terra e Subjetividade: A recriação da vida no limite do caos. Curitiba: Criar.

Gonçalves Filho, J. M. (2007). Humilhação social: Humilhação política. In B. P. Souza (Org.), Orientação à queixa escolar (pp. 1-30). São Paulo: Casa do Psicólogo.

Guattari, F. (1992). Caosmose: Um novo paradigma estético. São Paulo: Editora 34.

Leite, J. F., \& Dimenstein, M. (2011). Militância Política e Produção de Subjetividade: O MST em Perspectiva. Natal: EDUFRN.

Lopes, L. G. R., \& Carvalho, D. B. (2017). Juventude assentada e a identidade vinculada com a terra. Psicologia \& Sociedade, 29, 1-10. doi: 10.1590/1807-0310/2017v29159034

Lusa, G. M. (2013). O rural no semiárido e a transformação sócio-histórica de Alagoas. In L. S. Almeida, J. C. S. Lima, \& J. S. Oliveira (Orgs.), Terra em Alagoas: Temas e problemas (pp. 345-362). Maceió: EDUFAL.

Mesquita, M. R., Bonfim, J., Padilha, E., \& Silva, A. C. (2016). Juventudes e participação: Compreensão de política, valores e práticas sociais. Psicologia \& Sociedade, 28(2), 288-297. doi: 10.1590/1807-03102016v28n2p288

Movimento dos Trabalhadores Rurais Sem Terra. (2007). Textos para estudo e debate: $5^{o}$ Congresso Nacional do MST. São Paulo: MST.

Oliveira, O., \& Prado, M. A. M. (2013). A categoria juventude em contextos rurais: O dilema da migração. In J. F. Leite \& M. Dimenstein (Orgs.), Psicologia e Contextos Rurais (pp. 57-88). Natal: EDUFRN.

Paulo, M. A. L. (2013). Juventudes rurais nos pequenos municípios do Nordeste do Brasil. Uma breve reflexão acerca do desenvolvimento rural. In J. A. Menezes et al. (Orgs.), JUBRA: Territórios interculturais de juventude (pp. 325-342). Recife: EDUFPE.

Romagnoli, R. C. (2009). A cartografia e a relação pesquisa e vida. Psicologia \& Sociedade, 21(2), 166-173. doi: 10.1590/S0102-71822009000200003

Santos, F. T. (2009). A “recuperação” de assentamentos rurais em questão: A experiência do Assentamento Rendeira - Alagoas (Dissertação de mestrado). Programa de Pósgraduação em Ciências Sociais, Universidade Federal de Campina Grande, Campina Grande, Paraíba, Brasil. Recuperado de http://dspace.sti.ufcg.edu.br:8080/jspui/handle/riufcg/6227 
Souza, L. M., Marçal, M. M., Lino, T. R., Mayorga, C., \& Prado, M. A. M. (2012). Entre a nomeação e a instituição: Reflexões a partir da juventude rural no sindicato. In C. Mayorga, L. R. Castro, \& M. A. M. Prado (Orgs.), Juventude e a experiência do político no contemporâneo (pp. 99-120). Rio de Janeiro: Contra Capa.

Ximenes, V. M., \& Camurça C. E. S. (2016). Novos cenários da pobreza e da seca na zona rural nordestina: Suas implicações na saúde mental. In M. Dimenstein, J. F. Leite, J. P. Macedo, \& C. Dantas (Orgs.), Condições de vida e saúde mental em contextos rurais (pp. 175-194). São Paulo: Intermeios.

Varela, F., Thompson, E., \& Rosch, E. (1993). L'incription corporelle de l' esprit: Sciences cognitives et expérience humaine. Paris: Seuil.

Vinadé, T. F., \& Guareschi, P. A. (2007). Inventando a contra-mola que resiste: Um estudo sobre a militância na contemporaneidade. Psicologia \& Sociedade, 19(3), 68-75. doi: $10.1590 / \mathrm{S} 0102-71822007000300011$

\section{Endereço para correspondência}

\section{Jadielma de Barros Alves}

Rua Nossa Senhora das Dores, 124, Teotônio Vilela, Arapiraca - AL, Brasil. CEP 57311-660

Endereço eletrônico: jadi_alves@ hotmail.com

\section{Saulo Luders Fernandes}

Rua Roland Simons, 337 apto 101, Jatiúca, Maceió - AL, Brasil. CEP 57035-552

Endereço eletrônico: saupsico@gmail.com

\section{Marcos Ribeiro Mesquita}

Rua 4, 35, Cidade Universitária, Maceió - AL, Brasil. CEP 57073-086

Endereço eletrônico: marcos.mesquita@ip.ufal.br

Recebido em: 16/07/2019

Reformulado em: 19/06/2020

Aceito em: 02/07/2020

\section{Notas}

* Psicóloga, graduada pela Universidade Federal de Alagoas, 2019, mestrando pela Universidade Federal de Alagoas.

** Professor de Psicologia da Universidade Federal de Alagoas Campus Arapiraca. Professor Colaborador do Programa de Pós Graduação em Psicologia da UFAL.

*** Professor de Psicologia da Universidade Federal de Alagoas Campus A. C. Simões. Professor Permanente do Programa de Pós Graduação em Psicologia da UFAL. 
Jadielma de Barros Alves, Saulo Luders Fernandes, Marcos Ribeiro Mesquita

Este artigo de revista Estudos e Pesquisas em Psicologia é licenciado sob uma Licença Creative Commons Atribuição-Não Comercial 3.0 Não Adaptada. 